\title{
Editing Strategies of Chinese Product Texts of International Cross-Border E-Commerce Platforms
}

\author{
X. Caihong and L. Zeyu
}

\section{ABSTRACT}

In recent years, China's trade exports have continued to increase. With the advent of network information technology, cross-border E-commerce has entered people's lives, and has gradually been accepted by overseas buyers due to its efficiency, convenience and advanced features. There are strong demand for Chinese products in foreign markets. With the development of cross-border E-commerce in full swing, product text is becoming the focus of sellers. The thesis analyzes the development status of mainstream crossborder E-commerce platforms and Chinese product texts editing strategies, explains how to effectively incorporate texts into products.

Keywords: Business English, Chinese Product Texts, Editing Strategies, International Cross-Border E-commerce Platforms

Published Online: February 21, 2022

ISSN: $2736-5522$

DOI: $10.24018 /$ ejsocial.2022.2.1.200

\section{Caihong*}

Foreign Languages College, Hengyang Normal University, Hengyang Hunan, China.

(e-mail: 25697918@qq.com)

Lin Zeyu

Foreign Languages College, Hengyang Normal University, Hengyang Hunan, China.

(e-mail: 284438959@ qq.com)

*Corresponding Author

\section{INTRODUCTION}

With the development of information technology, the number of netizens in China is increasing. According to the statistics of the China Internet Network Information Center's "The 44th China Internet Development Program" report: as of June 2019, the number of Chinese Internet users reached 854 million, an increase of 25.98 million from the end of 2018, and the Internet penetration rate reached $61.2 \%$. With the increase of the number of Internet users, the use frequency of Internet mode is also significantly improved. The online shopping market maintains rapid development, and the model innovation of crossborder E-commerce provides new growth momentum for the online shopping market. With the popularization of the Internet and the support of related logistics and payment methods, government policies have promoted the steady development of cross-border E-commerce, and become an important means of the modern international trade.

Cross-border E-commerce refers to the E-commerce platforms and online trading platforms that are affiliated to different trading entities in different borders, through E-commerce platforms to achieve transactions, pay and settle accounts, and deliver goods and complete transactions through cross-border logistics. Since 2000, the number of overseas students has increased, the word "purchasing by proxy" has gradually entered people's vision, and foreign goods have begun to become popular. Ten years later, the rise of the Internet has driven the development of cross-border E-commerce. In 2014, the government officially recognized the mode of cross-border E-commerce, and cross-border E-commerce has entered a period of rapid development.

From the perspective of the development of cross-border E-commerce in China, the scale of transactions is expanding rapidly. In 2011, cross-border E-commerce accounted for only $6.8 \%$ of China's total imports and exports. In 2019, it rose to $32.7 \%$, an increase of five times, and the total amount exceeded 10 trillion RMB. The scale of cross-border online shopping users has also continued to grow. By 2018, the number of cross-border online shopping users in China has reached 88 million. With the improvement of cross-border E-commerce platforms services, more consumers will be attracted to buy products through cross-border Ecommerce platforms. The expansion of online shopping users has changed the dominant mode of crossborder E-commerce B2B transactions, small customers have sprung up, their unique needs and advantages test the rapid response and service capabilities of enterprises, under the trend of globalization, SMEs should seize the opportunity of cross-border E-commerce development and implement the "going out" strategies. 


\section{OVERAll Review of Cross-Border E-COMMERCE PlatForms}

With the popularization of national policies, the decline of traditional foreign trade, the market development, and the continuous entry of Chinese sellers, cross-border E-commerce has become a major hotspot in recent years, and it is likely to become the mainstream foreign trade export mode in the future under the environment of the epidemic situation, and promote the development of international trade in China for a long time. At present, the mainstream cross-border E-commerce platforms are Amazon, Alibaba International station, AliExpress, Wish, and eBay, etc. Although they are all playing the whole categories and selling global brands, they have their own characteristics. Different industry insiders will choose different platforms to carry out cross-border E-commerce platforms activities. This thesis mainly introduces the three platforms from their main situation, main categories, features and their development status.

\section{A. Amazon.com}

Amazon, the largest online E-commerce company in the United States, is located in Seattle, Washington. Amazon is one of the earliest companies that began to operate E-commerce on the Internet. Amazon was founded by Jeff Bezos on July 16, 1995. At the beginning, it only did the business of book sales. Now it has expanded to a very wide range, covering almost all other products. It has become the world's second largest online retailer with the variety of products and the world's second largest Internet enterprise. There are many products covered under the Amazon platform.

\section{B. Alibaba.com}

Alibaba International Station, as the world's largest B2B cross-border E-commerce platform, was established by Ma Yun in 1999. The first business sector of Alibaba Group, professional international export and overseas B2B cross-border trade platform, Alibaba International Station has served more than 26 million active enterprise buyers in more than 200 countries and regions, and the composite growth of payment buyers in the past three years has exceeded $100 \%$.

Alibaba international logistics has covered more than 200 countries and regions around the world, and will resonate with ecological partners to redefine global freight standards through digitalization. "Door-todoor" service capability is one of the key directions: goods are pulled from the factory to ports, declares customs, enters overseas ports by sea, land, and air, clears customs, pays taxes, and finally completes terminal delivery.

\section{Aliexpress.com}

Aliexpress, officially launched in April 2010, is Alibaba's only online trading platform for global markets, known as the "International Taobao". But Aliexpress faces overseas buyers, and also relies on Alibaba's international Alipay guarantee transactions, using international express delivery, which is the world's third largest English online shopping website. Aliexpress is an online trading platform for foreign trade integrating orders, payments and logistics that Alibaba helps small and SMEs enterprises to contact terminal wholesale retailers, sells rapidly in small quantities and batches, and expands profit space.

\section{Editing Strategies of Product TeXts of Cross-Border E-COMMERCE Platforms}

The 2019 White Paper on China's Cross-border E-commerce Export Trends and Opportunities shows that in the past five years, the proportion of cross-border E-commerce exports in foreign trade exports has increased from $2.2 \%$ to $7.7 \%$. In 2018, over 40\% of Amazon's new sellers came from China. At present, with the continuous expansion of the influence of Alibaba International Station, Amazon and AliExpress platforms, Chinese sellers have also begun to settle in and seize the market of cross-border E-commerce. Now that the cross-border E-commerce industry has entered a period of steady growth, sellers need to transform and upgrade all aspects of product, improve platform search rankings, and promote sales. One of the key point affecting product search ranking is the quality of product titles.

\section{A. Editing of Titles in Cross-Border E-commerce Platforms}

Compared with traditional foreign trade, cross-border E-commerce has great differences in trade methods and trade processes. Cross-border E-commerce texts is very different from traditional foreign trade English in content and writing characteristics. It must be highly valued and studied in depth in writing and teaching in order to expand the number of views and attract more customers.

Modern English grammar stipulates that when we compose a phrase or sentence, each component must have a reasonable logical and linguistic grammatical relationship. But, when editing cross-border Ecommerce products, various titles are composed of one or more words, phrases, so they should conform to the constraints of modern English grammar on the relationship between their components. But now, the titles of cross-border E-commerce products often deviate from the conventional syntax requirements, and this phenomenon is also very common on major E-commerce platforms. 
Therefore, the first thing is to write the title of the product. The title is the first impression, directly related to whether it can arouse the customer's desire to place an order. How to edit a perfect title and attract the attention of buyers is the focus of the most attention of all cross-border E-commerce sellers. Release of high-quality products with high exposure rates is the most basic task. If the naming is improper, the products cannot be searched by buyers, and the exposure of the products will be lacking, and the transaction will be even more unlikely. From the above situation, the preparation of product titles has become particularly important. A good title will not only accelerate the ranking of the product, but also increase the popularity, collection or sales of the e-store, and increase the natural ranking of the cross-border E-commerce platforms.

The title generally includes a variety of information such as product name, brand, material, size, and packaging. The vocabulary requires careful selection and screening by the seller. The following title is the first under the Amazon "Pillow" keyword.

Hotel/Home Medium Firm Polyester Hollow fiber Bed Sleeping cotton cover Pillow

Among them, "Hotel/Home" represents the use scene of the pillow, "Medium" represents the size,

"Firm, Polyester" represents the material used for the pillow, and the word "Pillow" is put to the end, because the title is later, the heat is higher. The title part needs to be basically supplemented with productrelated material, size and packaging information. Rich product information can improve buyers' awareness of the product.

For the arrangement of product titles, there are generally the following rules:

The product title length specified by Ali International Station is 128 characters. If it is a "window product" , it is better to fill it up, and the rest of the products only need simple editing, and make full use of the limited products to completely display your products, The core keywords must be placed behind or at the front within 45 characters of the title, and there are four reasons for requiring 45 characters.

First, this is the number of characters that the product can present to buyers, within the first 45 characters of 128 characters, and sellers need to show the most prominent features or functions of the product as much as possible, and set some selling points to attract buyers Click.

Second, because the rules of various platforms are different, the same keywords appear in different positions of the title, and the search weights of the products are different. Therefore, in order to improve the ranking, the core and high-level popularity words. of the product must also be placed in the first 45 characters.

Third, the same keyword can appear twice, preferably not more than three times or more, otherwise the product will be implicitly reduced or be judged as a search cheating, and at the same time, a limited and precious number of product characters will be wasted.

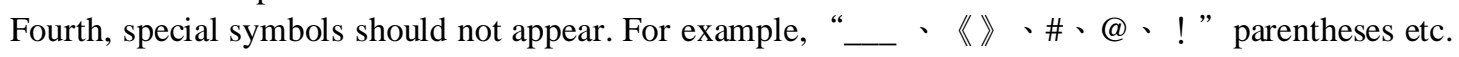
It is best to separate words with spaces, so that words can be combined with each other, but if special symbols are added between words, the highly popular words of the product are split, which in turn leads to a decrease in the search weight of the product.

In the process of writing the title, each platform also has the title requirements within the platform. Here is an example of Alibaba International Station:

The construction of the title generally has two essential elements: the first is attributing words + core words. This is a very basic type of product construction. According to other methods, professional operation experts have also proposed Configuration the second is selling point words + modifiers + core words and other more complex types of title construction. To put it simply, the first is the basic form of the title structure, and the degree of recognition, buyers can also understand the basic information of the product at a glance, and the second and other more complex configurations are the extended form of the title style.

The brand word of the product must be placed in the first letter of the title and must be capitalized. If there is no brand, fill in the product keyword directly. Try not to write the brand, except the brand is authorized or you own the brand). For example, if you want to sell iPhone products, you can put the model and brand behind it. (But in English, prepositions, definite articles, indefinite articles such as "of, with, in, for, an" and other function words) should be lowercase. Example: Hot selling Reloj intelligent smart watch Y68 health fitness tracker smart wristband for Y68 D20 smartwatch.

The title needs to be brief and clear, and not too long (the title of Ali International Station is about 128 characters, and the title of Amazon is roughly within 200 characters. It should be noted that whether it is punctuation or spaces, it must be counted as one character). Don't put all the popular words you think in the product name. Doing so is likely to cause Alibaba International Station to lower the rights of your store, and it is more likely to make customers think that your product information is not standardized. The title only needs to put high-profile words and precise words of the category.

It is forbidden to pile up vocabulary in the title, and the behavior of using certain words multiple times in the title of some products. For example, editing methods such as "shoes men", "shoes women" and "shoes sports" may violate Alibaba's platform rules, because most cross-border E-commerce platforms 
consider this to be an obvious search cheating and will give products Penalties for lower search rankings, which means that this has a negative impact on product rankings and thus affects page views. on the other hand, this also takes up a limited number of headline characters, and repeated invalid words will occupy more effective words. Therefore, it is necessary to avoid such situations. For example, you can change "shoes men/shoes women/shoes sports" to "women's shoes for men sports", so that buyers search for "shoes men", "shoes women", "shoes sports", etc. It is also possible to search these shoes.

Blind imitation often does not bring good results. The foreign language abilities of cross-border Ecommerce companies are currently uneven, and they are unable to set the title. Therefore, some of them use tools such as Google Translate to complete the translation, but they are prone to inaccurate expressions in foreign languages, some think they are highly imitations, or directly misappropriating the top search ranking titles for their own products. And it does not necessarily bring good traffic to the top products. If it is a new store, without the support of credit guarantee orders, hot words with a high similarity rate will not help the product to appear website ahead, if the product category market is different, the same word will also bring different effects. Therefore, it is particularly important to be able to write titles that belong to your own industry.

Enter a word that is not related to the product in the title, and the seller usually causes this situation: the seller of the product adds a word that does not match the product in the title to attract traffic. For example, the product is clearly "LCD screen", but "LED screen" is added to the title. If you also add the names of some well-known digital brands to increase traffic, this is also invalid. Buyers often find it difficult to distinguish the true attributes of the product when they see the title.

\section{B. Platforms Editing of Keywords in Cross-Border E-Commerce Platforms}

For novice sellers of cross-border E-commerce, understanding the keyword collection methods of products and the layout of product search keywords has become a necessary content for the operators of cross-border E-commerce platforms. In addition, for sellers, in the competition among peers, increase the page browsing time and conversion rates of products and increase the trading volume of e-stores. In this regard, the layout of keywords plays an important role. This part will analyze core words, modified words, selling point words, attribute words.

\section{1) Core words}

For products, the core word is the center of the entire product texts. All keywords in the title are extended from the core words, so the keywords in the entire title are closely related to the core words. And through the screening of the core words, we found this result:

Firstly, the frequency of the core words in the title has an impact on the ranking of search results. The higher the frequency of product core words, the higher the probability that the product will be ranked higher, and vice versa, the lower the ranking. But this is not entirely relevant, because the ranking of all products on the cross-border E-commerce platforms is not entirely dependent on keywords, and there are other factors that affect search rankings, such as product and service capabilities. On-time delivery rate of merchants, online order turnover, etc., the stronger the store's comprehensive ability, the higher the ranking of products and stores, and sellers with strong comprehensive capabilities are generally large sellers. Even if the core word frequency of a certain product title on the first page is slightly less than that of the second page, the comprehensive capabilities of these big sellers are stronger, so the platform can prioritize these stores and products on the first page to attract more of traffic.

It should be noted that multiple occurrences of core words will be regarded as search cheating, and the platform will filter and give different levels of ranking for post-processing such as "Digital air compressor inflator pump portable air pump tire inflator with emergency lighting inflator" Inflator appeared 3 times and was ranked on the fourth page.

"Digital air compressor inflator pump portable air pump tire inflator with emergency lighting inflator"

"Inflator" appeared 3 times and was ranked on the fourth Alibaba international station web page.

\section{2) Modified words}

In addition to the core words, more modifiers or adjectives can be added to the product texts to describe the product in an all-round way, answering the question of "what kind of product". For example, "noise reduction / high sound quality / headphone", "natural / low fat" milk and so on. The words in the quotation marks mentioned earlier can be called modifiers. Modified words generally include all kinds of information that customers need to know, such as product style, shape, size, color, material, model, quality, craftsmanship, popular elements, purpose or function, product characteristics, target group, us age mode, use Time, use effect, etc. When setting the title, you can select modifiers based on the buyers pay most attention to. For example, a buyer who wants to buy headphones may be concerned about the functions of noise reduction headphones (high sound quality/noise reduction), style (head-mounted/in-ear/) shape (round/cylindrical), Size and weight (254g), color (white/black), quality (high quality), style (cute/street/trend), purpose (study/work), suitable for the season (summer/winter), etc. 


\section{3) Selling point words}

The selling point of a product is essentially the reason for its consumption. In addition to core words and modifiers, you can also consider adding some selling points in the product title to attract sellers to click. The main task of selling point words is to strongly focus and highlight a certain characteristic of products and services, and leave an impression on buyers to reach orders. Theoretically speaking, buyers needs are different. Whether it is core words, parameter words or temptation words, they may become the selling point of the product. Therefore, the category of selling point words is very broad and can be used flexibly, such as high quality/pure natural etc.

\section{4) Attribute words}

Attribute words can indicate the material, detailed parameters, color and other information of the product. Different perspectives lead to different choice of attribute words. Almost every attribute word in the title needs to fully detail the characteristics of the product. Attribute words often describe miniskirts through these dimensions: length, color, fabric, collar type, decoration, pattern, color, size and packaging. A product plus an attribute word to combine a core word, such as "aluminum alloy vacuum flask" . In this way, our products can avoid the danger of competing with stronger sellers for the same hot words as much as possible. The attribute word plays a role of modification.

In addition to the above four types of vocabulary, people often hear long tail words, modifiers, precise words, hot words, category keywords, etc. It is worth noting that their referents are different, but there are considerable repetitions. Due to the short development history of the cross-border E-commerce industry and various rules are still in the process of constant regulation, these classification and naming methods are not very accurate and rigorous.

\section{Editing of Detail Pages in Cross-Border E-Commerce Platforms}

The product detail page is a page used to display detailed product information in all aspects. As the main page for product display in cross-border E-commerce, the detail page bears most of the store traffic and order volume. The time of customer stays on the detail page determines the transaction conversion rate, so a good product detail page can resonate with customers, so the copy description in the product detail page plays a icing on the cake. Most of the store's traffic and orders come from the conversion of the detail page, which is directly related to the store's exposure conversion rate. A high-quality product detail page can effectively increase the conversion rate of products, stimulate customers desire to place orders, establish customers trust in the store, allow customers to have a comprehensive understanding of products, dispel customer concerns, and facilitate customers to place orders. Therefore, cross-border E-commerce platform sellers must attach great importance to the optimization of product detail pages. To make customers interested in products, or even purchase products, it is very important to know the products and understand the products, including product specifications, features, and functions. Through the description and attribute parameters of the product, customers can have a basic understanding of the product in their minds.

The basic information form of the product is the first interface displayed to overseas buyers, which determines whether consumers are interested in continuing to browse.

The first part is the title. As mentioned earlier, the title is of great significance to E-commerce sellers. He decides whether the product can be searched by overseas buyers. The layout of the title in the details page plays a role in attracting traffic.

The second part is the product map, which can instantly transmit the function, appearance, or store information of the product, and then stimulate the consumer's desire to browse. The product map can intuitively show the buyer all aspects of the product information, and the texts cannot be transmitted. Information, pictures can often be done.

The third part is the display of the strength of the store. The details page mainly presents to the buyer a good product plus a strong company or manufacturer, such as the CE certificate of electronic products, the certification of SGS third-party organization, should let overseas buyers know that the product is a compliant product with no safety hazards.

The frame design of the detail page should conform to the consumer's way of thinking, and help buyers understand the product from the inside out, from perceptual to rational. The first clear product picture on the product details page determines whether the buyer has the desire to buy the product, and then through the description of various parameters in the product information table, it can deepen the consumer's more detailed understanding of the product. Secondly, it needs to be used real shot detail photo and comparisons are used to help consumers make rational decisions and place orders; finally, after-sales service information is used to dispel consumers order worries. If you reverse or disrupt the progressive order presented in the details page, it is easy to interrupt the consumer's habit of thinking. If the after-sales service of the product is put first without understanding the product, then the consumer may end it early Single behavior, at the same time, while presenting the product progressively, the details page should display the information of each part by clear division bars, and in this process, the irrelevant and invalid information should be 
excluded, so that the various information of the product is clear at a glance, everything is covered.

Successful texts design is not only derived from profound foreign language knowledge, but also inseparable from the specific embodiment of the product in life. After being concretized by texts, it is the main goal that consumers can read the texts smoothly. Therefore, it is necessary to align the combination of texts and product display with consumers, accurately locate the target, and grasp the product issues that they are most concerned about as the entry point, grasp the pain points of customers, and achieve marketing effects. There are two specific points to be done when editing the copy of the detail page:

\section{1) Precise, concise and powerful wording}

Concise, clear and precise wording is helpful for consumers to smoothly capture key information when browsing products. For example: "Wireless Active Noise Cancelling Headphones" product, the detail page adopts the core selling point of "Powerful Noise Reduction" to show the application scenarios of the product, highlighting that earphones can effectively reduce noise in various scenarios effect. At the same time, supplemented by the subtitle "Lightweight and Portable", customers can understand the comfort level of the headset, which accurately and cleverly reflects the characteristics and selling points of this product.

\section{2) Grasping the core selling point}

The main purpose of the texts of the detail page is that consumers need to be aware of the core selling point of the product in a short time. Therefore, while covering all aspects of the information, it is necessary for consumers to grasp the core selling point of our products. Therefore, at the beginning of the texts design, it is necessary to determine how to integrate the main characteristics of the product through the theme of the full texts, highlighting the core selling points. For example, analyze low-end headphones between 100 and 200 yuan. Common brands include oppo, Sennheiser, etc. The parameters of the products are roughly the same. The core selling points that can be selected are: full body waterproof, comfortable experience, and non-destructive sound quality; second selling points are: smart Charging, five-year warranty, combined promotional products include earmuffs for earphones, wearing bags, etc. Accurately grasp the core selling point, starting from the sound quality technology of the headset, not only the theme of the copy is clear, but the introduction of the selling point of the product is done in one go.

\section{CONCLUSION}

In the traditional trade activities in the past, the two main factors affecting the conversion rate only required the matching of product information with customers. Only price and quality are needed to make a transaction. In E-commerce activities, the transmission of various types of information directly affects customers purchasing decisions. Based on the analysis of product conversion rate in cross-border Ecommerce, this article analyzes the influencing factors of cross-border E-commerce product conversion rate from the three dimensions of "exposure, browsing, and purchase" based on the customer's purchase decision-making process. The keywords and titles of this article correspond to product exposures and clicks, allowing consumers to accurately find our products, and the decision to browse and purchase requires the information on the product details page, whether it can match the needs of consumers, Thereby prompting consumers to place orders smoothly.

A good product text for cross-border E-commerce is to attract more buyers, and a good title can make products stand out among others. However, it is unscientific to just guess the buyer's preference for keywords. In the age of traffic and data, the author believes that the ability to integrate and analyze data has become particularly important, and the ability to predict market products By following the trend, understanding the preferences of buyers, and avoiding cultural differences in different countries, product texts will become excellent, and products can be displayed vividly in front of buyers even thousands of miles away.

The layout of product texts requires our information to be gradual and in-depth. Grasp the customer's psychology. Under normal circumstances, businesses do not have strict and unified requirements for the layout of the texts. Creative designs can be made according to the structure and selling point of the product. However, in the design, attention should be paid to the core selling points of the texts to reflect the structure of the product. Gradually guide consumers to discover the core value of the product, so as to stimulate the user's buying behavior.

All in all, in today's era when cross-border E-commerce platforms are developing rapidly, product texts reflects extremely important marketing value. It can be seen that sellers should pay attention to the product texts, grasping the idea of writing the product as a whole, analyzing the specific needs of target users, and refining product selling points to write the actual detail page texts, so as to achieve the effect of increasing conversion rate and marketing products. In this era, product promotion is combined with Internet big data to explore more scientific and reasonable product promotion methods, accurate to target customers, and promote the development of my country's cross-border E-commerce industry. 


\section{ACKNOWLEDGMENT}

This paper is funded by Hunan Teaching Reform Research Project: Research and Practice of "Blended" Teaching Mode of Business English Based on National Standard (Project No.: Year 2019, No. 291, Item 661), by the horizontal project: On College-Enterprise Cooperative Talent Training Mode of Business English Majors Based on National Standard (Project No.: HXZXXQ202118), and by the provincial firstclass course "Business English Reading" of Hunan Province (Project No.: Year 2020, No. 9, Item 257).

\section{CONFLICT OF INTEREST}

Authors declare that they do not have any conflict of interest.

\section{REFERENCES}

Banghua, Z. (2017). Pragmatic Lingustic Explanation of Product Texts' Structure in Internation E-Commerce. Chengdu Normal University Journal, 88(5)

Evans, V. \& Green, M. (2014). Cognitive Linguistics:An Introduction. Beijing: World Publishing Corporation.

Ghose, A., Ipeirotis, P. G., Li, Beibei. (2014). Examining the Impact of Ranking on Consumer Behavior and Search Engine Revenue. Management Science, 60(7).

Jun, L. (2016). Analysis of Upgrading Strategies of Product Texts In Internation E-Commerce. Foreign Economy and Trade Practice, 63(4).

Khine, C. \& Nongpong, K. (2018). Harnessing Frequency and Language Features for Keyword Extraction on E-commerce P12)atforms. IOP Conference Series: Materials Science and Engineering, 428(1).

Lu, X. \& Zhao, X. (2014). Differential Effects of Keyword Selection in Search Engine Advertising on Direct and Indirect Sales. Journal of Management Information Systems, 30(4).

Qiaoyun, Fang. (2016). Decision and Upgrading of Products' Headlines in Internation E-Commerce. Foreign Economy and Trade Practice, 57(4).

Tesiero, J. (2016). Discovery of Long Tail Keywords in Paid Search. Journal of Applied \& Computational Mathematics, 5(4).

Wei, Y. (2019). Problem Analysis and Improving Approaches in Product Texts Design Based on Consumers' Needs. Electronic Commerce, 56(2).

Xiang, Z. (2019). Editing Approaches of Headlines in Operation of Cross-border E-Commerce. Modern Marketing, 222(1)

Xiaoli, Z., Xiaoxiao, H., \& Yue, X. (2021). Key Effects of Products' Turning Ratio in International E-Commerce. Introduction to Chinese Economy and Trade, 132(3). 